\section{EFFECTIVENESS OF VIRTUAL ENVIRONMENT DESENSITIZATION IN THE TREATMENT OF AGORAPHOBIA}

\author{
Max M. North, Sarah M. North, Joseph R. Coble \\ Clark Atlanta University \\ Atlanta, Georgia
}

Editor: Hans Sieburg

\begin{abstract}
The primary purpose of this study was to investigate the effectiveness of the virtual environment technology in the area of psychotherapy. Consequently, this study mvestigated the effectiveness of a virtual environment desensitization (VED) in the treatment of agoraphobia (fear of being in places or situations from which escape might be difficult or embarrassing). It was done with a traditional experimental design using $N=60$ subjects. Thirty subjects were placed in the experimental group and thirty subjects were placed in the control group. Two instruments were used: an Attitude Towards Agoraphobia Questionnaire (ATAQ) and the Subjective Unit of Discomfort Scale (SUDS). Only subjects in the experimental group were exposed to the VED treatment. The virtual environment desensitization was shown to be effective in treatment of subjects with agoraphobia (experimental group). The control group, or no-treatment group, did not change significantly. All the attitudes towards agoraphobic situation decreased significantly for the virtual environment desensitization group (experimental group) but not for control group. The average SUDS in each session decreased steadily across sessions, indicating habituation. This research, including the pilot studies, has established a new paradigm for utilizing virtual environment technology in the effective, economical, and confidential treatment of psychological disorders.
\end{abstract}

\section{Introduction}

Agoraphobia is one of the most serious and prevalent anxiety disorders in the field of mental health. It accounts for approximately 60 percent of all phobic disorders [9]. The American Psychiatric Association in the Diagnostic and Statistical Manual Disorders defines agoraphobia as fear of being in places or situations from which escape might be difficult or embarrassing [2]. Agoraphobic fears typically lead to a pervasive avoidance of a situation such as being alone, either outside the home or being in the home alone; being in a crowd of people; staying in a line; traveling in an automobile, bus, or airplane; or being on a bridge or in an elevator. People having this disorder suffer from marked distress about having the fear or from significant behavior difficulties. This behavior dysfunction causes interference with normal routines and/or with interpersonal relationships that can result in significant distress.

There have been relatively few publications of controlled research on the treatment of agoraphobia. However, behavioral therapy has included exposing the subject to anxiety-producing stimuli (technically called systematic desensitization). These stimuli are generated through a variety of modalities including imaginal (subject generates stimulus via imagination) and In Vivo (subject experiences real situations).

Research reviews demonstrate that in utilizing systematic desensitization, most of the clients appear to have difficulties imagining the prescribed, or relaxation, scene. They also express strong avoidance of experiencing real situations. This avoidance may be a learned behavior that appears to reduce the anxiety of clients, thus reducing their public embarrassment. Empirical studies also demonstrate that most clients express little trauma associated with real-world situations after treatment with systematic desensitization techniques.

Recently the practical application of the virtual environment (commonly known as virtual reality) has been extended to many diverse areas such as database, production design, and surgical simulation. Briefly, the virtual environment is a technology that enables users to enter computer-generated worlds and interface with their artificial environment through sight, sound, and touch [10]. The virtual environment offers a new humancomputer interaction paradigm in which users are no longer simply external observers of data or images on a computer screen. They are active participants within a computer-generated three-dimensional virtual world.

The virtual environment technology may be utilized to overcome some of the difficulties inherent in the 
traditional treatment of agoraphobia. Virtual environment, like current imaginal and In Vivo modalities, can generate stimuli that can be utilized in desensitization therapy. Like systematic desensitization therapy, virtual environment desensitization (VED) therapy can provide stimuli for clients who cannot imagine too well or are too phobic to experience real situations. Unlike systematic desensitization (i.e., In Vivo) techniques, therapist-administered VED can be performed within the confines of a room, thus avoiding public embarrassment and violation of client confidentiality. Similar to "lens-assisted In Vivo" [14], a virtual environment can generate stimuli of much greater magnitude than standard In Vivo techniques, providing for greater desensitization. The VED can prepare clients before they actually experience the real world, and since it is under client control, it appears safe and may prove to be more effective than conventional methods of treatment. VED can be used as a step in preparing clients for maintenance therapy involving self-directed In Vivo exposure. VED also offers the ability to isolate which virtual stimulus parameters are essential in generating a phobic response. Finally, VED adds the advantage of greater efficiency and economy in delivering the equivalent of systematic desensitization within the counselor's office.

In order to investigate the effectiveness of VED in treatment of agoraphobia on college students, a traditional experimental design was utilized. The sample of this study consisted of self-reports of $N=60$ undergraduate male or female students who were suffering from agoraphobia (more specifically, agoraphobia without history of panic disorder), and who were willing to participate in the study. After screening the subjects, the selected subjects were randomly placod in an experimental group of 30 students and a control group of 30 students. The VED (experimental) group was familiarized with the virtual environment equipment in the first session. For the subjects' subsequent sessions, individual counseling was conducted in a standard format. The site of this study was Atlanta, a large metropolitan city in the southeast. Clark Atlanta University was the targeted institution. Two instruments were used in this study, Attitude Towards Agoraphobia Questionnaire (ATAQ) and Subjective Unit of Discomfort Scale (SUDS). The ATAQ and SUDS were administrated at pre- and post-periods of the experiment. The collectod data were subjected to analysis of variance ( $t$-test) to determine the effectiveness of the VED.

\subsection{PURPOSE OF THE STUDY}

The primary purpose of this study was to investigate the effectiveness of the virtual environment technology in the area of counseling. Consequently, this study investigated the effectiveness of a virtual environment desensitization (VED) in the treatment of agoraphobia on a select group of undergraduate students attending Clark Atlanta University.

\subsection{RESEARCH QUESTIONS}

The research questions as perceived by these investigators were:

1) Would virtual environment desensitization (VED) treatment of clients with agoraphobia significantly affect experimental group performance?

2) Could virtual environment technology assist counselors in treating clients by providing virtual environments that are safe and under the control of those clients?

\subsection{NULL HYPOTHESES}

In carrying out the purpose of this study, the following null hypotheses were tested:

H01: There will be no statistically significant difference between the mean post-test scores of subjects in the control and experimental groups on the ATAQ.

H02: There will be no statistically significant difference between the mean pre- and post-test scores of the subjects in the experimental group on the ATAQ.

H03: There will be no statistically significant difference between the mean post-test scores of subjects in the control and experimental groups on the SUDS.

H04: There will be no statistically significant difference between the mean pre- and post-test scores of the subjects in the experimental group on the SUDS.

\subsection{SIGNIFICANCE OF THE STUDY}

This research is expected to contribute significantly to the existing body of knowledge on the treatment of psychological problems, specifically in the treatment of agoraphobia. The outcome may provide specific significant contributions to the research area of 
counseling and establish a new paradigm for utilizing virtual environment technology in the effective, economical, and confidential treatment of psychological problems.

The results of the study may provide specific significant contributions to the areas of psychotherapy, virtual environments, and human-computer interaction by:

1. Providing altemative techniques for treatment of agoraphobia.

2. Expanding the impact of virtual environment technology to combat other psychological problems; obsessive/compulsive disorders; and phobic behavior modifications.

3. Advancing emerging technology in the virtual environment area by attracting researching advances from the fields of counseling, psychology, computer science, engineering, and mathematics.

4. Prompting researchers to search for applications of virtual environment in their own fields of expertise.

5. Elevating public awareness of virtual environment technology beyond its present entertainment and business applications by promulgating its possibilities to enhance human conditions.

\subsection{ASSUMPTIONS}

Some basic assumptions were made in conducting this study:

1. It was assumed that the participants in this study would show significant reductions in anxiety levels if they were exposed to safe, supportive experimental activities through virtual environment desensitization.

2. It was assumed that the phenomenon of regression toward the mean would not favor one group over another since the groups were randomly assigned. To ensure the balance between the experimental and control groups, participants were screened so that the independent variables of age and education were within a close range.

\subsection{LIMITATIONS OF THE STUDY}

This study was confined to undergraduate students currently enrolled at Clark Atlanta University. The study involved a population of 60 students. Generalizations from the finding of this study should be limited to situations that do not differ significantly from the situations in this current study. The instruments of this study were of a self-reporting nature. Thus the validity of the data was dependent upon the attitude, honesty, and accuracy of the participants' responses.

\subsection{DEFINITTON OF TERMS}

Agoraphobia (without history of panic disorder): A fear of being in places and situations from which escape might be difficult or embarrassing.

Desensitization: A graduated exposure of the client to the anxiety-invoking stimuli.

In Vivo techniques: A exposure of client to the anxiety-involing stimuli in the real world rather than the imaginary world.

Virtual Environment: A computer-generated world that allows users an interactive interaction through the use of sight, sound, and touch.

Virtual Environment Desensitization (VED): The use of virtual environment technology as an alternative to systematic desensitization and self-directed maintenance systematic desensitization.

\section{Brief Review of the Literature}

The literature review for this research study was divided into the following sections: (1) nature of agoraphobia, (2) traditional treatments for agoraphobia, (3) computer applications in psychotherapy, (4) concept of a virtual environment, and (5) virtual environments and psychotherapy.

\subsection{NATURE OF AGORAPHOBIA}

Recent studies report that anxiety disorders are frequently found in the general population. Simple phobias, such as agoraphobia, have been reported as the most common form of anxiety disorder. [2]

Agoraphobia is the abnormally intense fear of being in places or situations from which escape might be difficult or embarrassing. [2] People having this disorder suffer marked distress, and behavior dysfunction involves interference with normal routines and/or with interpersonal relationships.

Specifically, persons with agoraphobia restrict their activities, including being outside the home, in crowds, in a line, on a bridge, on an elevator, and traveling in a bus, train, car, or airplane. Usually these persons anticipate or suffer from a "limitod symptom attack", that is, developing a single or small number of symptoms. The physiological symptoms may include dizziness, falling, loss of bladder or bowel control, vomiting, cardiac distress, depersonalization, and derealization. In most 
cases such symptoms have occurred in the past and a person anticipates they will reoccur. Usually the person avoids situations that may induce such anxiety.

\subsection{TRADITIONAL TREATMENT FOR AGORAPHOBLA}

Traditional counseling and psychotherapy have treated phobias primarily by behavioral appoaches. [6] In particular, the use of systematic desensitization has been well documented. [12]

\subsection{COMPUTER APPLICATTONS IN PSYCHOTHERAPY}

One of the most significant developments of the past decade has been the impact of computer technology on our daily lives. Computers have become integral components of education, communication, entertainment, etc. Computer applications in psychology and counseling exemplify the new trend of computer applications. [7],[8] Specifically, many different functions may be carried out by individuals interacting with a computer. Examples include problem solving, information decimation and instruction in decision-making strategies, testadministration and interpretation, etc.

\subsection{CONCEPT OF A VIRTUAL ENVIRONMENT}

Virtual Environment offers a new human-computer interaction paradigm in which users are no longer simply extemal observers of data or images on a computer screen but are active participants within a computergenerated three-dimensional virtual world. A virtual environment differs from traditional displays in that computer graphics and various display and input technologies are integrated to give the user a sense of presence or immersion in the virtual environment. [15] The interaction of computer and various input and display technologies can create the sense of immersion in a computer generated reality, which is referred to as immersive virtual environments. [3]

Virtual reality is a technology that enables users to enter computer-generated worlds and interface with its three-dimensionally through sight, sound, and touch. [10] Virtual reality also is called virtual environment, telepresence, artificial worlds, cyberspace, or multisensory Input/Output. The power of the virtual reality is that users can treat virtual objects as if they were real.

Today, virtual reality research is conducted by government, industry, academic, and others (e.g. NASA Ames Research Center, IBM, Boeing Co., University of
North Carolina in Chapel Hill, University of Washington). Furthermore, many researchers see virtual reality as a way to meet human needs by creating intelligent, people-centered products, with applications in business, entertainment, and education.

\subsection{VTRTUAL ENVIRONMENTS AND PSYCHOTHERAPY}

Although the past two years have seen increasing interest in applications of virtual reality to psychology and psychopathology, there have been few controlled studies to document its effectiveness. A news report of the existence of a study similar to this study, conducted at Kaiser-Permanente, has been reported in CyberEdge Journal [19], although analytic results were not presented. In Japan, VR was used to simulate the sand play projective technique with autistic children [17]. Again, no data were presented, but the authors contended that the VR sand play was useful.

In a recent pilot collaborative study (1992 thru 1994) [11],[13],[16] conducted by six researchers 1 , an application of virtual environment and psychotherapy seems to be the first known controlled study in this field. This pilot research investigated the effectiveness of virtual environment graded exposure in the treatment of acrophobia (fear of heights). Subjects for this pilot research were twenty students who were randomly assigned to one of the two groups, a virtual environment graded exposure (ten subjects) or a waiting list control group (ten subjects). The findings of this study were very encouraging. The major conclusion of this unique research study indicated that the virtual environment was successful in the treatment of clients with acrophobia. Thus in addition to current In Vivo and imaginal modalities, it was concluded that virtual environments can also generate stimuli for use in desensitization therapy.

\section{Research Methodology}

\subsection{EXPERIMENTAL DESIGN}

The design of this study was the traditional experimental design. The researcher selected $N=60$ subjects for this study. Thirty subjects were placed in the experimental group and thirty subjects were placed in the

\footnotetext{
1 The three authors of this paper plus Larry Hodges (Graphics, Visualization \& Usability Center, College of Computing, Georgia Institute of Technology, James Williford (Department of Psychiatry and Neurology, Eisenhower Army Medical Center), and Barbara Rothbaum (Department of Psychiatry, Emory University)
} 
control group. The independent variable of this study was the effectiveness of virtual environment desensitization treatment on subjects who suffer from agoraphobia. The dependent variables of this research were the Attitude Towards Agoraphobia Questionnaire (ATAQ) and Subject Unit of Discomfort Scale (SUDS) instruments.

\subsection{SITE AND SETTING}

The site of this study was Atlanta, a large metropolitan city in the southeast. Clark Atlanta University was the targeted institution.

\subsection{SUBJECTS POOL AND SAMPLE}

The subject pool consisted of a select group of undergraduate students (males and females) who attended Clark Atlanta University. The sample of this study consisted of $N=60$ undergraduate male and female students who were suffering from agoraphobia and who were willing to participate in the study.

\subsection{SELECTION PROCEDURE}

Subjects were recruited through questionnaires distributed to undergraduate students enrolled in undergraduate courses at Clark Atlanta University. The questionnaires contained questions that screened students for agoraphobia according to diagnostic and statistical manual disorders, and excluded subjects with history of panic disorder. Additional screening criteria included in the questionnaire were a symptom duration of at least one year and a strong motivation toward overcoming agoraphobia. Subjects rated their maximum level of ansiety during the test on a ten-point ATAQ and a tenpoint SUDS. Subjects with an anxiety rating of less than two and more than eight on the ATAQ and/or SUDS were excluded from the study. Remaining subjects were randomly assigned to one of two groups: an experimental group (VED group) and a waiting list (control group).

\subsection{MEASURING THE RESULTS}

Two instruments were used in this study. [4],[5] The first instrument was a modified ATAQ [1]. The ATAQ has twelve different attitude attributes measures (six pairs of antonyms attributes) on a rating scale ranging from zero to ten. These attributes are: good-bad, nice-awful, pleasant-unpleasant, safe-dangerous, unthreateningthreatening, and harmless-harmful. The second instrument was a modified SUDS [17]. SUDS is comprised of a ten-point rating scale from zero to ten that will be reported in intervals of every five minutes by subjects during the VED treatment.

\subsection{APPARATUS}

The virtual environment system for this study consisted of a stereoscopic head-mounted display (VR Flight Helmet), an electromagnetic head-tracker (Ascension Technology Bird), and a glove (Virtual Technologies CyberGlove) worn by the user for interacting with objects in the virtual environment. Interactive imagery was generated by software developed at the Graphics, Visualization \& Usability Center at Georgia Tech and the Human-Computer Interaction Group at Clark Atlanta University, executing on a Silicon Graphics workstation and pentium-based personal computer. This arrangement allowed for time-parallel stereoscopic display with visual panning controlled by head movement in all virtual directions.

\subsection{VIRTUAL ENVIRONMENT SCENES}

VREAM $^{\circledR}$ and SVE ("Simple Virtual Environments") software were used to create the following virtual environment scenes for this study:

1) A Series of Balconies Scene \{\{photo 1\}\} - The balconies model consisted of several balconies attached to a tall building. Four balconies were created at different heights: ground level, second floor (six meters), tenth floor (thirty meters), and twentieth floor (sixty meters).

2) An Empty Room Scene \{\{photo 2\}\} - The empty room scene was created using four walls, ceiling, and floor. The room was four by six meters in size with only one door and no windows.

3) A Dark Barn Scene $\{$ photo 3\}\} - The dark barn model was a barn in an open field. The interior of the barn was black (simulating darkness). The barn had a wide opening for entrance so subjects could exit the barn as quickly as they wished. There were several dark colored objects inside the barn.

4) A Dark Barn with a Black Cat Scene $\{$ photo 4\}\} A black cat was simulated on the top of an object within the dark barn. The, subject had to enter barm and look to the right side to see the cat.

5) A Covered Bridge Scene \{\{photo 5\}\} - The covered bridge scene contained a bridge (ten meters high) that spanned a river and had walls on each side as well as a ceiling. There were two windows on each side of the walls and dark colors were used to simulate a dark, closed environment. 
6) An Elevator Scene \{\{photo 6\}\} - The elevator was modeled as an open elevator (no walls or ceiling) located on the inside of a 49 story hotel.

7) A Canyon with Series of Bridges Scene \{́photo 7\}) - The canyon model contained a series of bridges of different heights spanning the canyon from one side to the other. A river ran through the bottom of the canyon. The bridges varied not only in height but also in apparent steadiness. The lowest two bridges $(7 \mathrm{~m}$ and $50 \mathrm{~m}$ above the canyon floor) appeared safe and solid. The highest bridge $(80 \mathrm{~m}$ above the canyon floor) was a rope bridge with widely spaced wooden slats as the walkway.

8) A Balloons Scene \{\{photo 8\}\} - A series of balloons at different height was created for this scene. The first balloon was twenty meters off the ground. The second balloon was at thirty meters height, and the third balloon was at forty meters height. The scene also included a single-story building and a fourfloor office building.

\subsection{TREATMENT PROCEDURES}

Only subjects in the experimental group were exposed to the VED treatment. In the initial treatment session, the VED subjects were familiarized, as a group, with the virtual environment equipment. For the VED subjects' subsequent eight sessions, individual virtual environment desensitization counseling were conducted in a standard format. The computer program designed for VED generated a standard hierarchy of phobic situations. All measures were administered under blind conditions and in a standard order. A post-test of all subjects was obtained to complete an ATAQ and SUDS, including degrees for worsening symptoms and the degree to which their agoraphobia symptoms had changed since the pretests (ATAQ and SUDS). The durations of the activities were as follows:

Activity

Duration

1)

First session:

Group session were familiarized subjects with virtual environment equipment

2)

Subsequent Sessions:

Exposed subjects to VED treatment

60 hours and administered ATAQ for each subject. Then the expenimenters collected data for SUDS. Each session was about 15 minutes in length.

\subsection{STA7TSTTCAL TREATMENTS OF DATA}

The data collected from ATAQ and SUDS instruments were subjected to a statistical treatment consisting of an analysis of variance ( $t$-test) applied to determine significant differences between the means scores of the experimental group and/or the control group.

\subsection{RESEARCH PERIOD}

This research commenced on Feburary 1, 1993 and terminated on Feburary 17, 1995.

\section{Results}

The purpose of the study was to investigate the effectiveness of a virtual environment desensitization (VED) in the treatment of agoraphobia.

Null hypothesis $\mathrm{H} 01$ was designed to determine the mean difference between post-test scores of the subjects in the control and experimental groups on the ATAQt may be stated as

H01: There will be no statistically significant difference between the mean post-test scores of subjects in the control and experimental groups on the ATAQ

The results of the $t$-test indicated that there exists a significant difference between the mean post-test scores of the subjects in the control and experimental groups on the ATAQ $(t=3.196, d f=58, p<0.05)$. (Table 1)

TABLE 1

$t$-TEST RESULTS OF THE MEAN POST-TEST SCORES OF THE SUBJECTS IN THE CONTROL AND EXPERIMENTAL GROUPS ON THE ATAQ

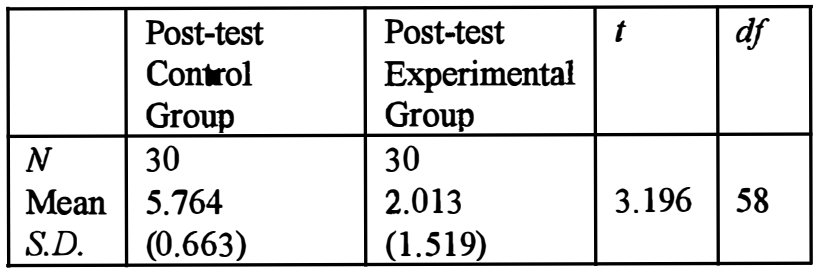

The $t$-value was 3.196 , which indicated statistically significant difference at the 0.05 level. Due to this significant difference, null hypothesis $\mathrm{H} 01$ was rejected. That is, there was a statistically significant difference between the mean post-test scores of the subjects in the control and experimental groups on the ATAQ.

Null hypothesis $\mathrm{H} 02$ was designed to determine the mean difference between pre- and post-test scores of the 
subjects in the experimental group on the ATAQ. It may be stated as

H02: There will be no statistically significant difference between the mean pre- and post-test scores of the subjects in the experimental group on the ATAQ.

The results of the $t$-test indicated that there exists a significant difference between the mean pre- and post-test scores of the subjects in the experimental group on the $\operatorname{ATAQ}(t=3.065, d f=58, p<0.05)$. (Table 2$)$

TABLE 2

$t$-TEST RESULTS OF THE MEAN PREAND POST-TEST SCORES OF THE SUBJECTS IN THE EXPERIMENTAL GROUP ON THE ATAQ

\begin{tabular}{|l|l|l|l|l|}
\hline & $\begin{array}{l}\text { Pre-test } \\
\text { Experimental } \\
\text { Group }\end{array}$ & $\begin{array}{l}\text { Post-test } \\
\text { Experimental } \\
\text { Group }\end{array}$ & $t$ & $d f$ \\
\hline$N$ & 30 & 30 & 3.065 & 58 \\
Mean & 5.487 & 2.013 & 3.06 \\
S.D. & $(0.938)$ & $(1.519)$ & & \\
\hline
\end{tabular}

The t-value was 3.065 , which indicated statistically significant difference at the 0.05 level. Due to this significant difference, null hypothesis $\mathrm{H} 02$ was rejected. That is, there was a statistically significant difference betwoen the mean pre- and post-test scores of the subjects in the experimental group on the ATAQ.

Null hypothesis $\mathrm{H} 03$ was designed to determine the mean difference between post-test scores of the subjects in the control and experimental groups on the SUDS. It may be stated as

H03: There will be no statistically significant difference between the mean post-test scores of subjects in the control and experimental groups on the SUDS.

The results of the $t$-test indicated that there exists a significant difference between the mean post-test scores of the subjects in the control and experimental groups on the SUDS $(t=3.084, d f=58, p<0.05)$. (Table 3$)$

The $t$-value was 3.084 , which indicated statistically significant difference at the 0.05 level. Due to this significant difference, null hypothesis $\mathrm{H} 03$ was rejected. That is, there was a statistically significant difference between the mean post-test scores of the subjects in the control and experimental groups on the SUDS.
TABLE 3

$t$-TEST RESULTS OF THE MEAN POST-TEST SCORES OF THE SUBJECTS IN THE CONTROL AND EXPERIMENTAL GROUPS ON THE SUDS

\begin{tabular}{|l|l|l|l|l|}
\hline & $\begin{array}{l}\text { Post-test } \\
\text { Control } \\
\text { Group }\end{array}$ & $\begin{array}{l}\text { Post-test } \\
\text { Experimental } \\
\text { Group }\end{array}$ & $t$ & $d f$ \\
\hline$N$ & 30 & 30 & 3.084 & 58 \\
Mean & 5.531 & 2.04 & \\
S.D. & $(0.718)$ & $(1.401)$ & & \\
\hline
\end{tabular}

Null hypcthesis H04 was designed to determine the mean difference between pre- and post-test scores of the subjects in the experimental group on the SUDS. It may be stated as

H04: There will be no statistically significant difference between the mean pre- and post-test scores of the subjects in the experimental group on the SUDS.

The results of the $t$-test indicated that there exists a significant difference between the mean pre- and post-test scores of the subjects in the experimental group on the SUDS $(t=2.956, d f=58, p<0.05)$. (Table 4)

TABLE 4

$t$-TEST RESULTS OF THE MEAN PREAND POST-TEST SCORES OF THE SUBJECTS IN THE EXPERIMENTAL GROUP ON THE SUDS

\begin{tabular}{|l|l|l|l|l|}
\hline & $\begin{array}{l}\text { Pre-test } \\
\text { Experimental } \\
\text { Group }\end{array}$ & $\begin{array}{l}\text { Post-test } \\
\text { Experimental } \\
\text { Group }\end{array}$ & $t$ & $d f$ \\
\hline$N$ & 30 & 30 & 2.956 & 58 \\
Mean & 5.241 & 2.04 & 58 \\
S.D. & $(0.699)$ & $(1.401)$ & & \\
\hline
\end{tabular}

The t-value was 2.956 , which indicated statistically significant difference at the 0.05 level. Due to this significant difference, null hypothesis $\mathrm{H} 04$ was rejected. That is, there was a statistically significant difference between the mean pre- and post-test scores of the subjects in the experimental group on the SUDS.

The mean SUDS for each of the eight VED sessions are presented in Table 5 and Graph 1. The data indicated that the average SUDS in each session decreased steadily across sessions, indicating habituation. 
TABLE 5

MEAN SUDS ACROSS ALL SUBJECTS FOR EACH OF THE EIGHT SESSION (EXPERIMENTAL GROUP)

\begin{tabular}{|c|c|}
\hline Session & Mean SUDS (S.D.) \\
\hline One & $5.66(0.735)$ \\
Two & $5.54(0.736)$ \\
Three & $5.24(0.765)$ \\
Four & $4.54(0.797)$ \\
Five & $3.72(1.029)$ \\
Six & $3.25(1.188)$ \\
Seven & $2.76(1.215)$ \\
Eight & $2.42(1.381)$ \\
\hline
\end{tabular}

\section{GRAPH 1}

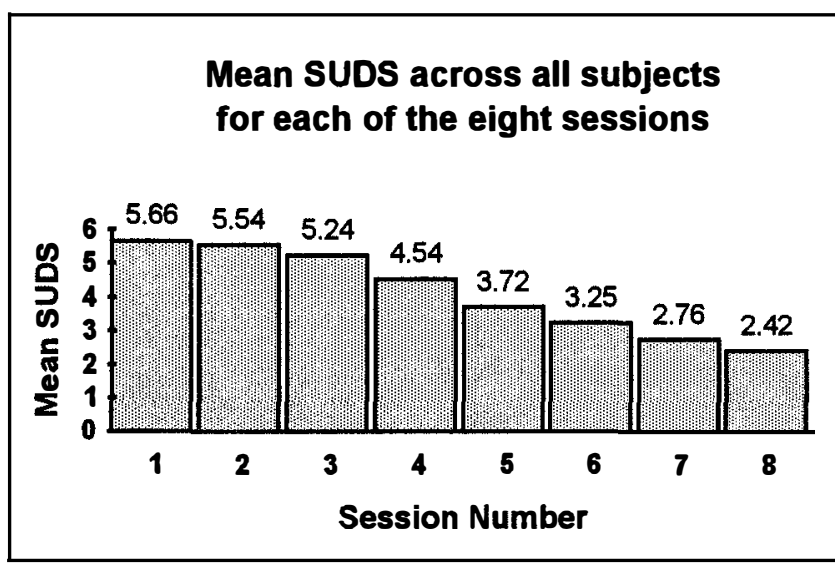

In general, Table 5 and Graph 1 show the superior habituation of agoraphobia of the experimental group utilizing the VED over the control group that received no treatment.

\section{Discussion}

The current experiment demonstrated that agoraphobic clients can be successfully treated with VED. In addition, the results of this study demonstrated that computers (i.e., virtual environments) can be a viable resource as a psychotherapy tool. [11],[13],[16] Specifically, the VED can provide clients with an important alternative opportunity for systematic desensitization and self-directed maintenance systematic desensitization, while assuring confidentiality.

In summary, this appear to be the first extensive known controlled study of the application of virtual environment to the treatment of a psychological disorder. The results indicated that the VED was very effective in reducing self-reported anxiety of the experimental group, whertas the contsol group did not demonstrate any sigusficant change
Theoretically, the present results are remarkable for many reasons. They attest to the sense of presence experienced by subjects in the virtual environment. The degree of anxiety and habituation observed would not have occurred if the subjects did not immerse in virtual environment. In addition, it seems that the fear structures of the subjects were activated (increases in anxiety) and modified (increases in habituation). The results also appeared to indicate that stimuli and responses were directly manipulated via virtual environment desensitization and habituation. [11],[13],[16]

\section{Conclusions}

This research, including the pilot studies, has established a new paradigm for utilizing virtual environment technology in the effective, economical, and confidential treatment of psychological disorders. Based on the findings of the study, the following conclusions seemed warranted:

1) The VED was effective in treatment of subjects with agoraphobia (experimental group).

2) The control, or no-treatment, group did not change significantly.

3) All the attitudes towards the agoraphobic situation decreased significantly for the VED group (experimental group) but not for the control group.

4) The average SUDS in each session decreased steadily across sessions, indicating habituation.

\section{Implications}

According to this study, there was a significant difference between the pre-mean scores of the virtual environment desensitization group (experimental group) and the post-mean scores of the experimental group. The implications of these results are numerous. Some of these are listed below:

1) Providing alternative techniques for treatment of agoraphobia.

2) Expanding the impact of virtual reality technology to combat other psychological disorders.

3) Establishing a new paradigm for utilizing virtual environment technology effectively, economically, and confidentially in the treatment of other psychological disorders.

4) Advancing emerging technology in the virtual environment and prompting researchers to search for application of virtual environment in their fields of expertise. 


\section{Recomendations}

The Implications drawn from the conclusions of this study seemed to warrant the following recommendations:

1) That this study be replicated using instruments such as the EEG and EMG to collect physiological data in conjunction with psychological data and thus more objectively validate the results of the study.

2) That virtual environment desensitization be developed and experimented with other psychological disorders.

3) That virtual environment desensitization be utilized by practitioners as an alternative technique for treatment of psychological disorders such as, agoraphobia.

4) That more research be conducted in other areas of counseling to determine effectiveness of the virtual environment technology.

\section{ACKNOWLEDGEMENTS}

This research project was sponsored by a grant from Boeing Computer Services (Virtual Systems Department), partially supported by U.S. Army Center of Excellence in Information Science under contract number DAAL03-92-6-0377. The views contained in this document are those of the author and should not be interpreted as representing the official policies of the U.S. Government, either expressed or implied.

\section{REFERENCES}

[1]J. L. Abelson, and G. C. Curtis, "Behaviour Research and Therapy", Vol. 27, 1989, p. 561.

[2]American Psychiatric Association, Diagnostic and Statistical Manual Disorders, Fourth Edition. Washington, DC, American Psychiatric Association, 1994, pp. 393-444.

[3]S. Bryson, "Survey of Virtual Environment Technologies and Techniques." Computer Science Corporation, Applied Research Branch, Numerical Aerodynamic Simulation Systems Division, MST0451, NASA Ames Research Center, ACMSIGGRAPH '92 Course Notes (1992).

[4]C. R. Derogatis, R. S. Limpman, K. Rickels, E. H. Uhlenhuth, and L. Coul, "The HSCL: A Self Report Inventory", Behavioral Sciences, Vol. 19 , 1974, pp. 1-15.

[5]J. E. James, B. A. Hampton, and S. A. Larsen, "The Relative Efficacy of Imaginal and In Vivo Desensitization in the Treatment of Agoraphobia",
Journal of Behavioral Therapy \& Experimental Psychiatry, Vol. 14, 1983, pp. 203-207.

[6]A. E. Kazdin, and L. A. Wilcoxon, "Systematic Desensitization and Non-specific Treatment Effects: A Methodological Evaluation", Psychiatric Bulletin, 1983, pp. 93-103.

[7]L. L'Abate, Programmed Writing: A Selfadministered Approach for Interventions With Individuals, Couples, and Families, Pacific Grove, CA: Brooks/Cole, 1991.

[8] L. L'Abate, and K. Platzman, "Programmed Writing (PW) in Therapy and Prevention With Families", American Journal of Family Therapy, Vol. 19, 1991.

[9]L. Michelson, M. Mavissakalian, and K. Marchione, "Cognitive and Behavioral Treatment of Agoraphobia: Clinical, Behavioral, and Psychophysiological Outcomes", Journal of Counseling and Clinical Psychology, Vol. 53, 1985, pp. 913-925.

[10] H. P. Newquist, "Virtual Reality's Commercial Reality", Computer World, 1992.

[11] M. M. North, and S. M. North, "Virtual Environments and Psychological Disorders", Electronic Journal of Virtual Culture, Vol. 2, No. 4, 1994.

[12] M. G. Pendelton, and R. L. Higgins, "A Comparison of Negative Practice and Systematic Desensitization in the Treatment of Acrophobia", Journal of Behavioral Therapy and Experimental Psychiatry, Vol. 14, 1983, pp. 317-323.

[13] B. O. Rothbaum, L. F. Hodges, D. Opdyke, Rob Kooper, J. S. Williford, and M. M. North, "Effectiveness of Computer-Generated (Virtual Reality) Graded Exposure in the Treatment of acrophobia", American Journal of Psychiatry, Vol. 152 , No. 4, 1995 , pp. 626-628.

[14] J. W. Schneider, "Lens-Assisted In Vivo Desensitization to Heights", Journal of Behavior Therapy \& Experimental Psychiatry, Vol. 13, 1982, pp. 333-336.

[15] T. B. Sheridan, "Musing on Telepresence and Virtual Presence", PRESENCE, Teleoperations and Virtual Environments, Vol. 1, No. 1, 1992, pp. 120126.

[16] J. S. Williford, L. F. Hodges, M. M. North, and S. M. North, Sarah, "Relative Effectiveness of Virtual Environment Desensitization and Imaginal Desensitization in the Treatment of Acrophobia", Proceedings of Graphics Interface '93 Conference, 1993), pp. 162.

[17] J. Wolpe, The Practice of Behavior Therapy, New York: Pergamon, 1969. 
[18] Hirose, M.; Hirota, K.; Kijima, R., "Human Behaviour in Virtual Environments", Proc. SPIE, Vol. 1666,1992 , pp. 548-559.

[19] Lamson, R. J., "Virtual Therapy of Anxiety Disorders", CyberEdge Journal, March/April 1994, p. 1 ff.

\section{BIOGRAPHIES}

MAX M. NORTH obtained his M.S. in computer Science from Jackson State University and his Ph.D. in Counseling and Human Development (Cognitive Science) from Clark Atlanta University, in 1995. He is Assistant Professor of Computer \& Information Science and Director of the Human-Computer Interaction Group \& Virtual Display Systems Laboratory. He is the author of many articles in the field of computing and psychology and recipient of an award from Sigma Xi Scientific Research Society.

Dr. North's field of research is human-computer interaction/interface. Specifically, his work focuses on studying "sense of presence" in virtual environments and designing virtual environments to study human-spatial perception and performance behavior in virtual environments.

Dr. North's current projects include $i$ ) the use of virtual reality in the treatment of psychological disorders (in collaboration with Boeing Computer Services Virtual Systems, Emory University, Ga. Tech., and U.S. Army Psychiatry Department), ii) the human-spatial perception and performance for two different driving behaviors in a virtual environment (in collaboration with the U.S. Army Center of Excellence for Research on Training and the Psychology Department of Georgia Tech.).

\section{Contact Information:}

Max M. North

Human-Computer Interaction Group \&

Virtual Display Systems Laboratory

Clark Atlanta University

Atlanta, Georgia, 30314

Phone: 404-880-6942

Fax: 404-880-6963

Email: max@acm.org

SARAH M. NORTH obtained her M.S. in Computer Science from Atlanta University, and she expects to receive her Ph.D. in Counseling and Human Development (Cognitive Science) from Clark Atlanta University in 1996. She is Assistant Professor of
Computer and Information Science and Co-director of Human-Computer Interaction Group and Virtual Display Systems Laboratory. She is the author of several articles in the field of computing and psychology.

Professor North's field of research is cognitive science and psychology. Her field of research is cognitive science and human-computer interaction and focuses on the effectiveness of virtual environments in the motivational processes of learners.

Professor North's current projects include $i$ ) the study of effectiveness of virtual environments for improving and maintaining intrinsic motivation of learners, and $i$ ) the development of better information visualization tools to support the characteristic of the human cognitive process.

\section{Contact Information:}

Sarah M. North

Computer and Information Science Department

Clark Atlanta University

Atlanta, Georgia, 30314

Phone: 404-880-6957

Fax: 404-880-6963

Email: sarah@acm.org

JOSEPH R. COBLE obtained his M.S. and Ph.D. in Psychology from Florida State University. $\mathrm{He}$ is Professor of Psychology and Chair of the Department. $\mathrm{He}$ has published several papers in the field of psychology and computing. By training, Dr. Coble is a research psychologist in the Psychobiology program at Florida State University (masters in human vision, doctorate in behavioral genetics).

Dr. Coble is basically a self-taught computer expert. His computer work has been primarily in the area of computer assisted instruction. He has been involved in several grants sponsored by the Minority Science Improvement Program (Department of Education), helping teach CAI techniques to minority college faculty. He has also served as Assistant Project Director of a project for training college faculty in CAI techniques and is currently serving as System Manager for the CAU BBS, a wide-area network aimed at providing technical help and useful educational programs to minority school faculty members across the country.

\section{Contact Information:}

Joseph R. Coble, Chair

Psychology Department

Clark Atlanta University

Atlanta, Georgia, 30314

Phone: 404-880-8259

Email: jcoble@cau.auc.edu 